Supporting Information for

\title{
Multilayer Approach for Advanced Hybrid Lithium Battery
}

Jun Ming,* Mengliu Li, Pushpendra Kumar, Lain-Jong Li*

Physical Sciences and Engineering Division, King Abdullah University of Science and Technology, Thuwal, 23955-6900, Kingdom of Saudi Arabia

*To whom correspondence should be addressed: (J. Ming) jun.ming@kaust.edu.sa; (L. J. Li) lance.li@kaust.eda.sa;

KEYWORDS: hybrid battery, multilayer, sulfur, lithium titanium oxide, operando Raman 
Table S1 Theoretical capacity of lithium-sulfur battery in step-sized electrochemical reactions.

\begin{tabular}{cc}
\hline Main step-sized electrochemical reactions & Theoretical capacity/ $\mathrm{mAh}^{-1 \dagger}$ \\
\hline $\mathrm{S}_{8}+2 \mathrm{Li}^{+}+2 \mathrm{e}^{-} \rightarrow \mathrm{Li}_{2} \mathrm{~S}_{8}$ & 209.38 \\
$\mathrm{Li}_{2} \mathrm{~S}_{8}+2 / 3 \mathrm{Li}^{+}+2 / 3 \mathrm{e}^{-} \rightarrow 4 / 3 \mathrm{Li}_{2} \mathrm{~S}_{6}\left(2 \mathrm{~S}_{3} *^{-}\right)$ & 69.79 \\
$\mathrm{Li}_{2} \mathrm{~S}_{6}+\mathrm{Li}^{+}+\mathrm{e}^{-} \rightarrow 3 / 2 \mathrm{Li}_{2} \mathrm{~S}_{4}$ & 139.59 \\
$\mathrm{Li}_{2} \mathrm{~S}_{4}+2 / 3 \mathrm{Li}^{+}+2 / 3 \mathrm{e}^{-} \rightarrow 4 / 3 \mathrm{Li}_{2} \mathrm{~S}_{3}$ & 139.59 \\
$\mathrm{Li}_{2} \mathrm{~S}_{3}+\mathrm{Li}^{+}+\mathrm{e}^{-} \rightarrow 3 / 2 \mathrm{Li}_{2} \mathrm{~S}_{2}$ & 279.18 \\
$\mathrm{Li}_{2} \mathrm{~S}_{2}+2 \mathrm{Li}^{+}+2 \mathrm{e}^{-} \rightarrow 2 \mathrm{Li}_{2} \mathrm{~S}$ & 837.54 \\
\hline
\end{tabular}

${ }^{\dagger}$ Theoretical capacity was calculated by the equation of $\mathrm{C}=\mathrm{NA}^{*} \mathrm{q}^{*} \mathrm{n} / 3.6 / \mathrm{M}_{\mathrm{s}}$, in which NA, $\mathrm{q}, \mathrm{n}$ and $\mathrm{M}_{\mathrm{s}}$ are the Avogadro constant (i.e., $6.02214 \times 10^{23} \mathrm{~mol}^{-1}$ ), elementary charge (i.e., $1.602176 \times 10^{-19} \mathrm{C}, 1 \mathrm{mAh}$ $=3.6 \mathrm{C}$ ), number of transferred electron and molar mass of sulfur participated in the reaction respectively 
Table S2 Capacity ratio of $\mathrm{Q}_{1} / \mathrm{Q}_{\text {slop }}$ and $\left(\mathrm{Q}_{1}+\mathrm{Q}_{\text {slope }}\right) / \mathrm{Q}_{2}$ in the $1^{\text {st }}$ cycle compared with previous results in lithium-sulfur batteries.

\begin{tabular}{|c|c|c|c|c|c|c|}
\hline Kind of Electrode $^{\dagger}$ & $\begin{array}{c}\text { Total } \\
\text { Capacity }\end{array}$ & $\overline{Q_{1}}$ & $\mathrm{Q}_{\text {slope }}$ & $\mathrm{Q}_{2}$ & $\begin{array}{c}\mathrm{Q}_{\text {solpe }} / \mathrm{Q}_{1} v s \\
\left(\mathrm{Q}_{1}+\mathrm{Q}_{\text {slope }}\right) / \mathrm{Q}_{2}^{\dagger \dagger}\end{array}$ & Reference \\
\hline Super P-S@graphite@LTO & 1675 & 321 & 218 & 1136 & 0.679 vs. 0.474 & This work \\
\hline CMK-3/S & 1000 & 133 & 87 & 780 & 0.654 vs. 0.282 & {$[1]$} \\
\hline $\mathrm{S}^{-\mathrm{TiO}_{2}}$ yolk-shell $(0.2 \mathrm{C})$ & 1010 & 225 & 125 & 660 & 0.556 vs. 0.530 & {$[2]$} \\
\hline Porous carbon spheres/S & 1190 & 190 & 120 & 880 & 0.631 vs. 0.352 & {$[3]$} \\
\hline Graphene-S & 1500 & 300 & 200 & 1000 & 0.667 vs. 0.500 & {$[4]$} \\
\hline Carbon spheres/S (0.25C) & 800 & $<20$ & $<10$ & $\sim 770$ & 0.500 vs. 0.039 & {$[5]$} \\
\hline Sulfur-rich polymer $(0.2 \mathrm{C})$ & 1050 & 200 & 100 & 750 & 0.500 vs. 0.400 & {$[6]$} \\
\hline $\mathrm{S} @ \mathrm{GDL}(0.12 \mathrm{C})$ & 1300 & 200 & 130 & 970 & 0.650 vs. 0.340 & [7] \\
\hline Carbon nanotube $/ \mathrm{NiFe}_{2} \mathrm{O}_{4}-\mathrm{S}$ & 1350 & 250 & 150 & 950 & 0.600 vs. 0.421 & {$[8]$} \\
\hline N-doped hollow carbon/S & 1140 & 200 & 130 & 810 & 0.520 vs. 0.407 & [9] \\
\hline Polyacrylonitrile/S (0.2C) & 1300 & 200 & 110 & 990 & 0.550 vs. 0.313 & {$[10]$} \\
\hline $\mathrm{S} / \mathrm{MnO}_{2}(0.05 \mathrm{C})$ & 1300 & 250 & 150 & 900 & 0.600 vs. 0.444 & [11] \\
\hline $\begin{array}{l}\text { S/hollow mesoporous } \\
\text { titania@Carbon nanotubes }\end{array}$ & 1560 & 300 & 150 & 1110 & 0.500 vs. 0.405 & [12] \\
\hline Stacked graphene-S & 1200 & 250 & 150 & 800 & 0.600 vs. 0.500 & {$[13]$} \\
\hline $\mathrm{S} / \mathrm{Ti}_{2} \mathrm{C}$ (Mxene) (0.05C) & 1420 & 265 & 165 & 1000 & 0.623 vs. 0.420 & [14] \\
\hline
\end{tabular}

\footnotetext{
'If without noting the current density, the electrode was performed at the rate of $0.1 \mathrm{C}$.

${ }^{\dagger}$ The ratio of $\mathrm{Q}_{\text {slope }} / \mathrm{Q}_{1}$ and $\left(\mathrm{Q}_{1}+\mathrm{Q}_{\text {slope }}\right) / \mathrm{Q}_{2}$ are more accurate for comparing the results because it can avoid the error resulted from the mass of active materials (i.e., sulfur) in the electrode. The longer discharge curve of $\mathrm{Q}_{\text {slope }}$ comparing to $\mathrm{Q}_{1}$ with the highest ratio value of 0.679 demonstrate that a lot of soluble sulfur species are well trapped in the layer of graphite/LTO and then could be reacted to contribute a high capacity. And also, a high ratio of $\left(\mathrm{Q}_{1}+\mathrm{Q}_{\text {slope }}\right) / \mathrm{Q}_{2}$ demonstrate that a good protection of sulfur species avoiding their dissolution/migration towards lithium anode side.
} 

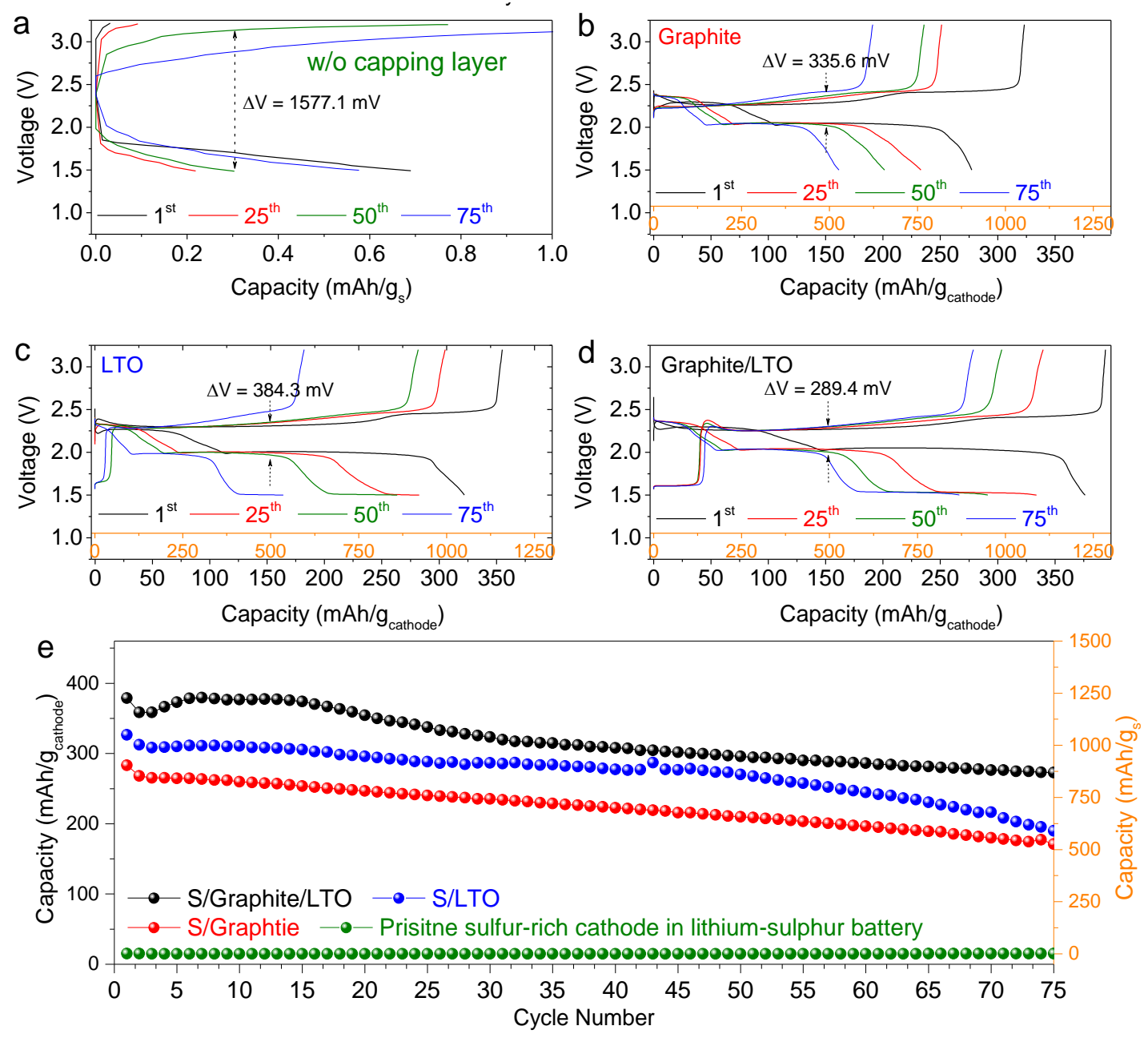

Figure S1. Electrochemical performances of the batteries with different cathodes. Typical voltage vs. capacity profiles of batteries (a) with pristine S-rich cathode, (b) S/graphite, (c) S/LTO and (d) S/graphite/LTO cathodes at the high rate of 1C. The voltage polarization of batteries were compared at the capacity of $0.3 \mathrm{mAh} \mathrm{g}_{\mathrm{s}}^{-1}$ ( $v s$. pristine S-rich cathode) and 500 $\mathrm{mAh} \mathrm{g}_{\text {cathode }}{ }^{-1}$ respectively. The complete disappearance of discharge-charge platforms for pristine sulfur-rich cathode may result from the insulation of sulfur cathode at a high rate of $1 \mathrm{C}$. (e) Cycling performance of the batteries with various cathodes. 

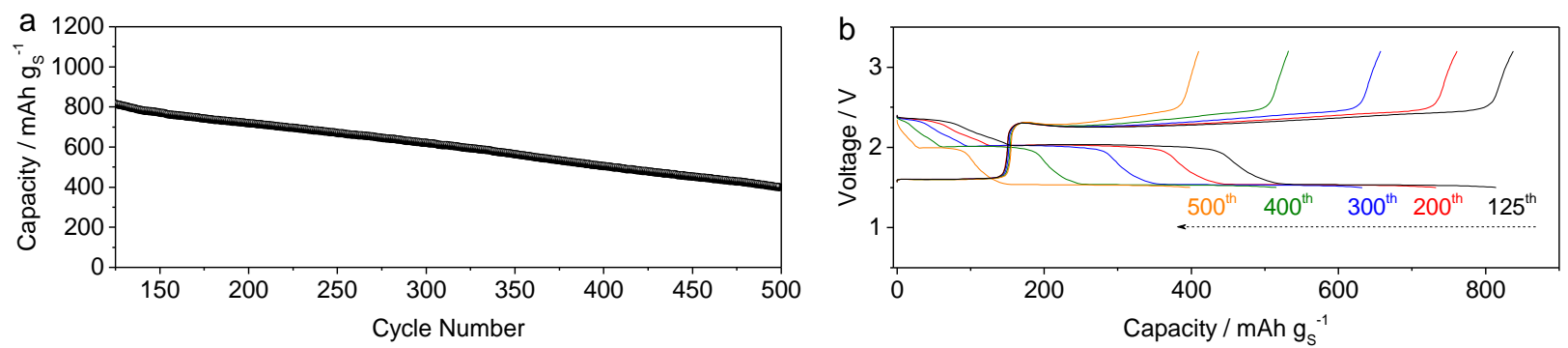

Figure S2. Electrochemical performance of hybrid battery. (a) Continued cycle ability and (b) typical voltage $v s$. capacity profiles in initial 500 cycles.
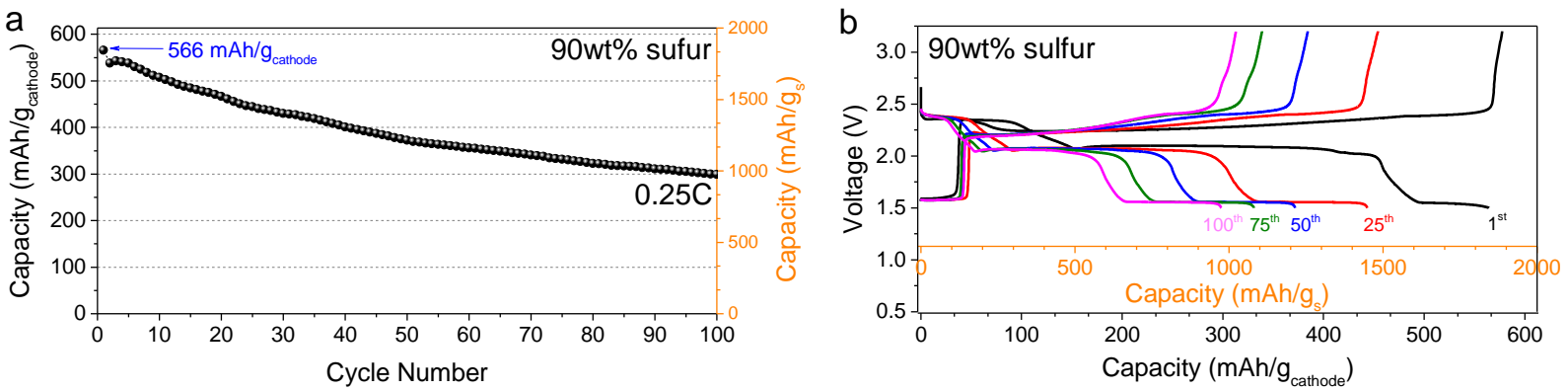

Figure S3. Electrochemical performances of hybrid batteries with 90wt\% S/graphite/LTO. (a) Cycling performances and (b) typical voltage vs. capacity profiles of batteries at the rate of $0.25 \mathrm{C}$ 

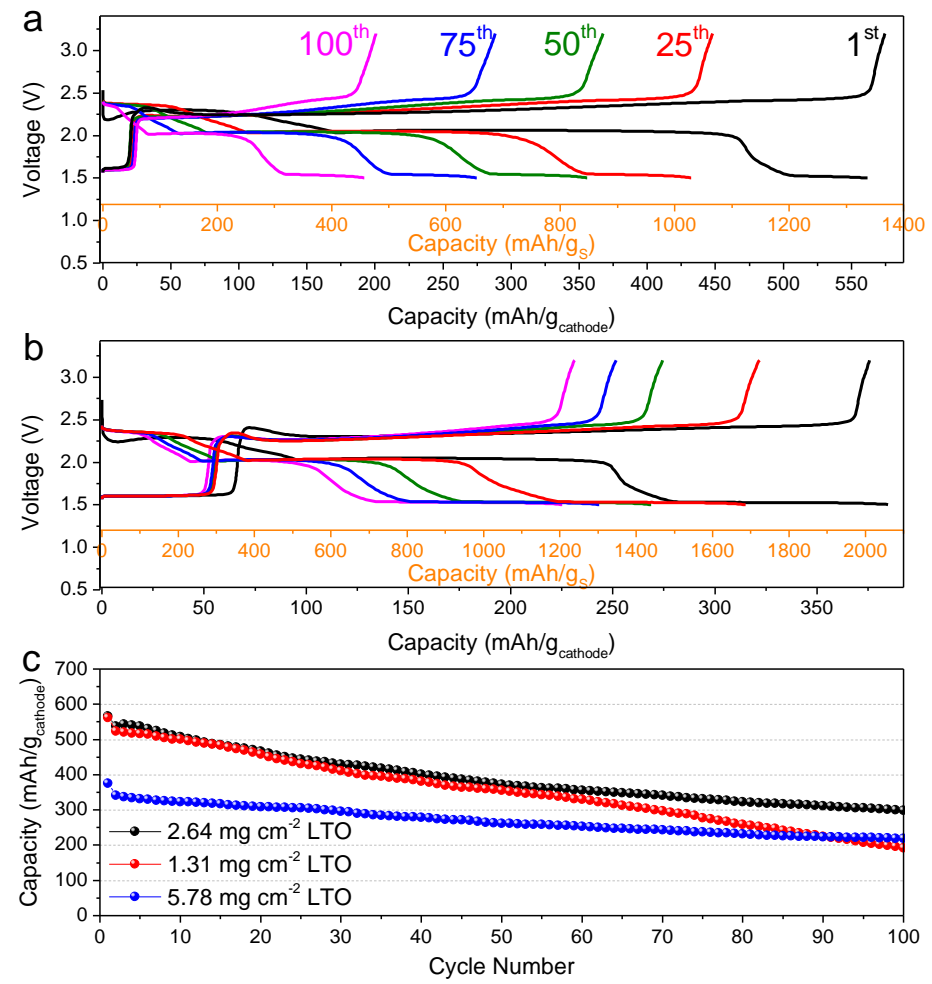

Figure S4. Electrochemical performance of hybrid battery with different mass density of LTO on S/graphite/LTO. Typical voltage vs. capacity profile of battery using the electrode of (a) S/graphite/LTO (1.5:0.75:1.31 $\mathrm{mg} \mathrm{cm}^{-2}$ ) and (b) S/graphite/LTO (1.5:0.75:5.78 $\mathrm{mg} \mathrm{cm}^{-2}$ ). (c) Comparative cycle performance of electrodes using variable mass density of LTO. Reducing the mass density of LTO from $2.64 \mathrm{mg} \mathrm{cm}^{-2}$ to $1.31 \mathrm{mg} \mathrm{cm}^{-2}$, a low capacity contribution of LTO was demonstrated. Increasing the mass density to $5.78 \mathrm{mg} \mathrm{cm}^{-2}$, the stability is largely improved, but the capacity versus total mass of cathode reduced because of the high amount of LTO. Varying the mass density of LTO, we can finely design the kind of battery with desirable performances according to the specific requirement.
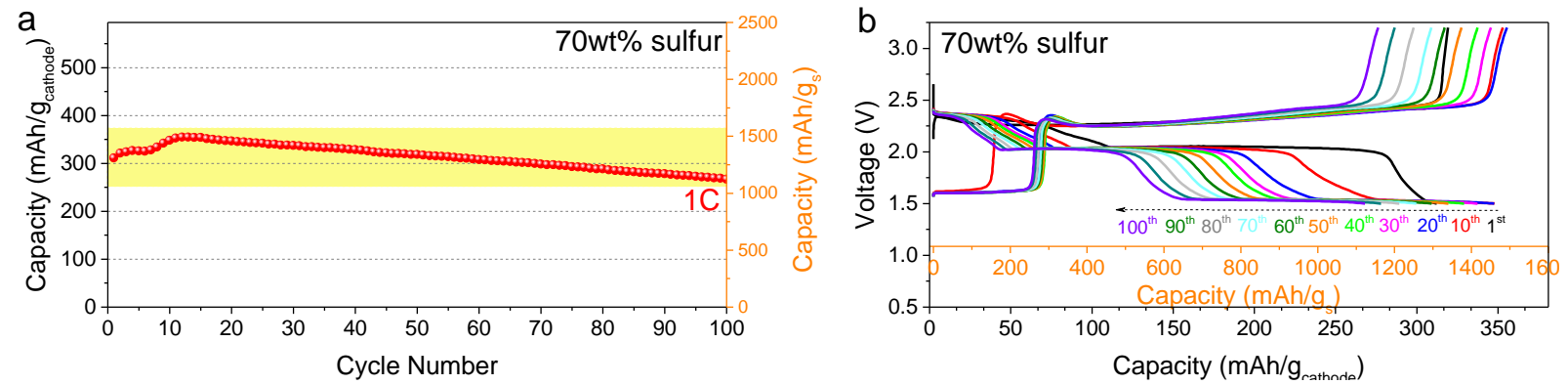

Figure S5. Electrochemical performances of hybrid batteries with S(70wt\%)/Graphite/LTO. (a) Cycling performances and (b) typical voltage $v$ s. capacity profiles of batteries at the rate of $1 \mathrm{C}$. 

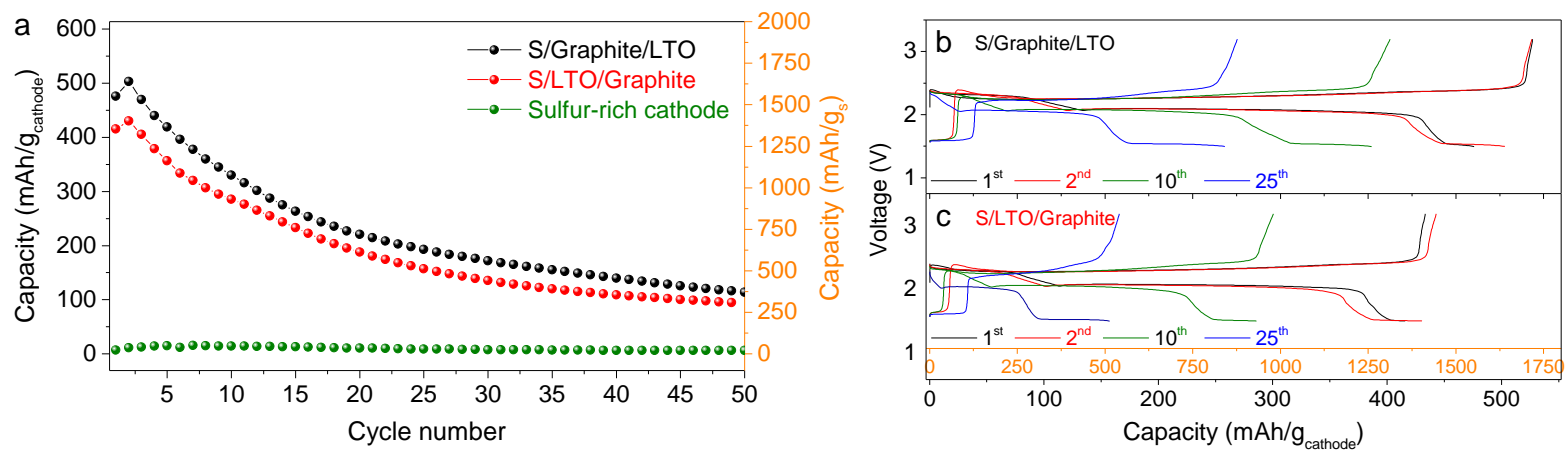

Figure S6. Electrochemical performances of hybrid battery at high temperature of $60{ }^{\circ} \mathrm{C}$. (a) Comparative cycle ability and typical voltage vs. capacity profiles of batteries with the (b) S/graphite/LTO and (c) S/LTO/graphite under the rate of $1 \mathrm{C}$ at the high temperatures of $60{ }^{\circ} \mathrm{C}$.
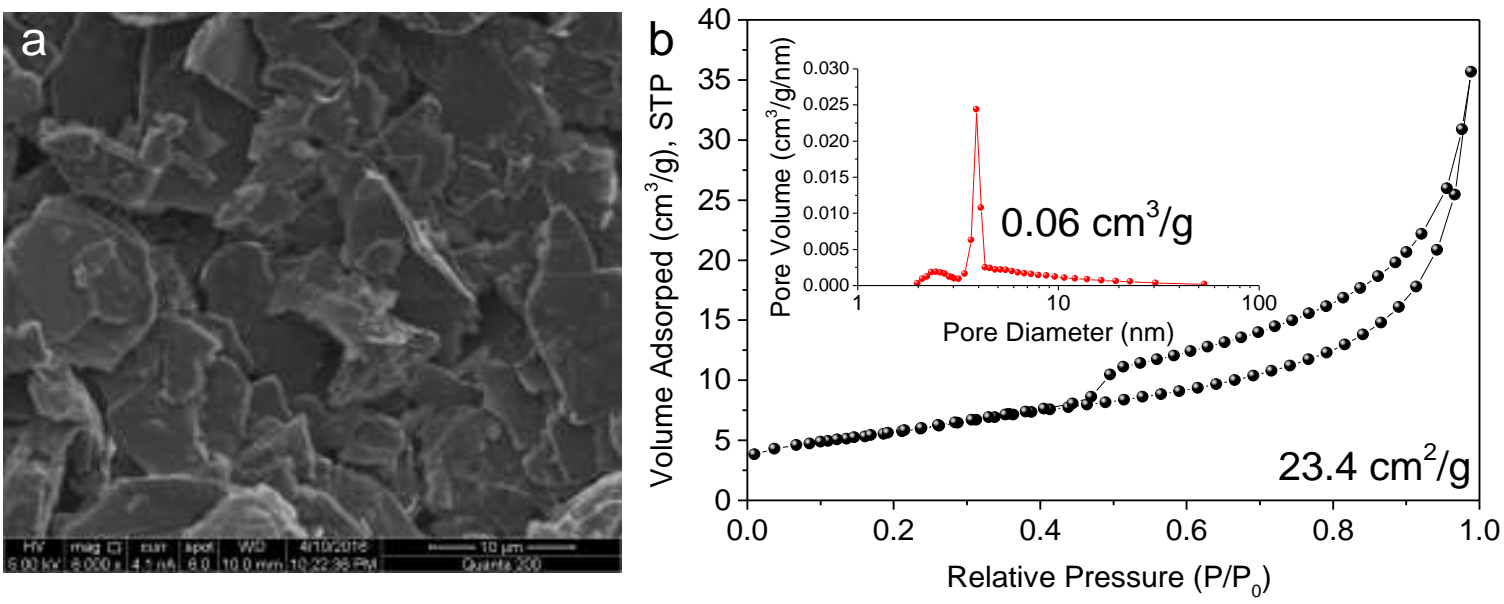

Figure S7. Characteristics of graphite. (a) SEM image and (b) $\mathrm{N}_{2}$ adsorption-desorption isotherm of graphitic sheets, which has typical feature of the Type H3 loop rich of meso-pores. Inset of (b) is the curve of pore volume $v s$. pore dimeter demonstrating the pore diameter distribution. 

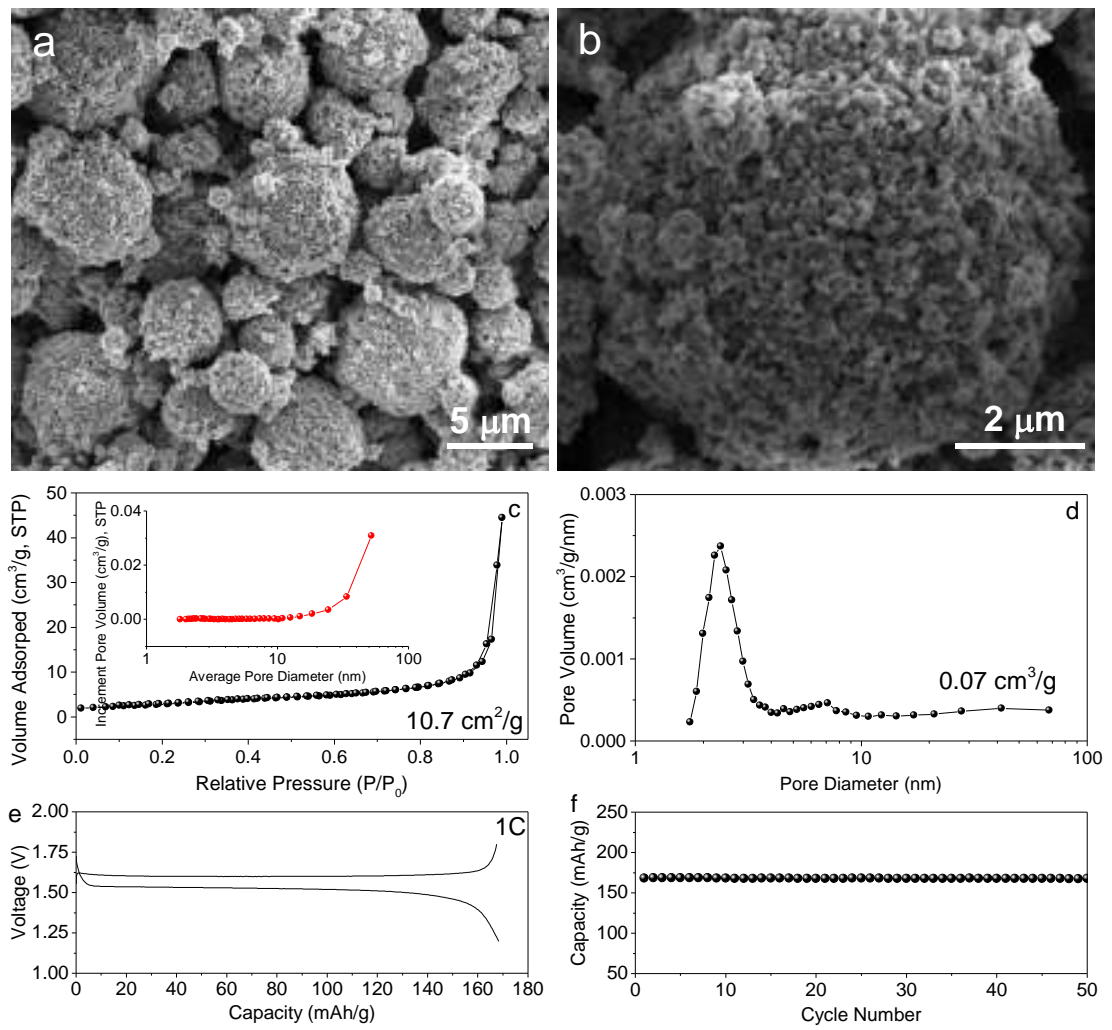

Figure S8. Characterizations of $\mathrm{Li}_{4} \mathrm{Ti}_{5} \mathrm{O}_{12}$ (i.e., LTO) particles. (a, b) SEM images of LTO with different magnification. (c) $\mathrm{N}_{2}$ adsorption-desorption isotherm and (d) pore diameter distribution of LTO. Inset of (c) is the curve of increment pore volume vs. average pore dimeter. (e) Typical voltage $v s$. capacity profiles and (f) cycle performance of LTO at 1C using ether-based LiTFSI electrolyte. Meanwhile, the LTO particles are also rich of the pores with the size larger than 100 $\mathrm{nm}$ visualized by SEM images. 


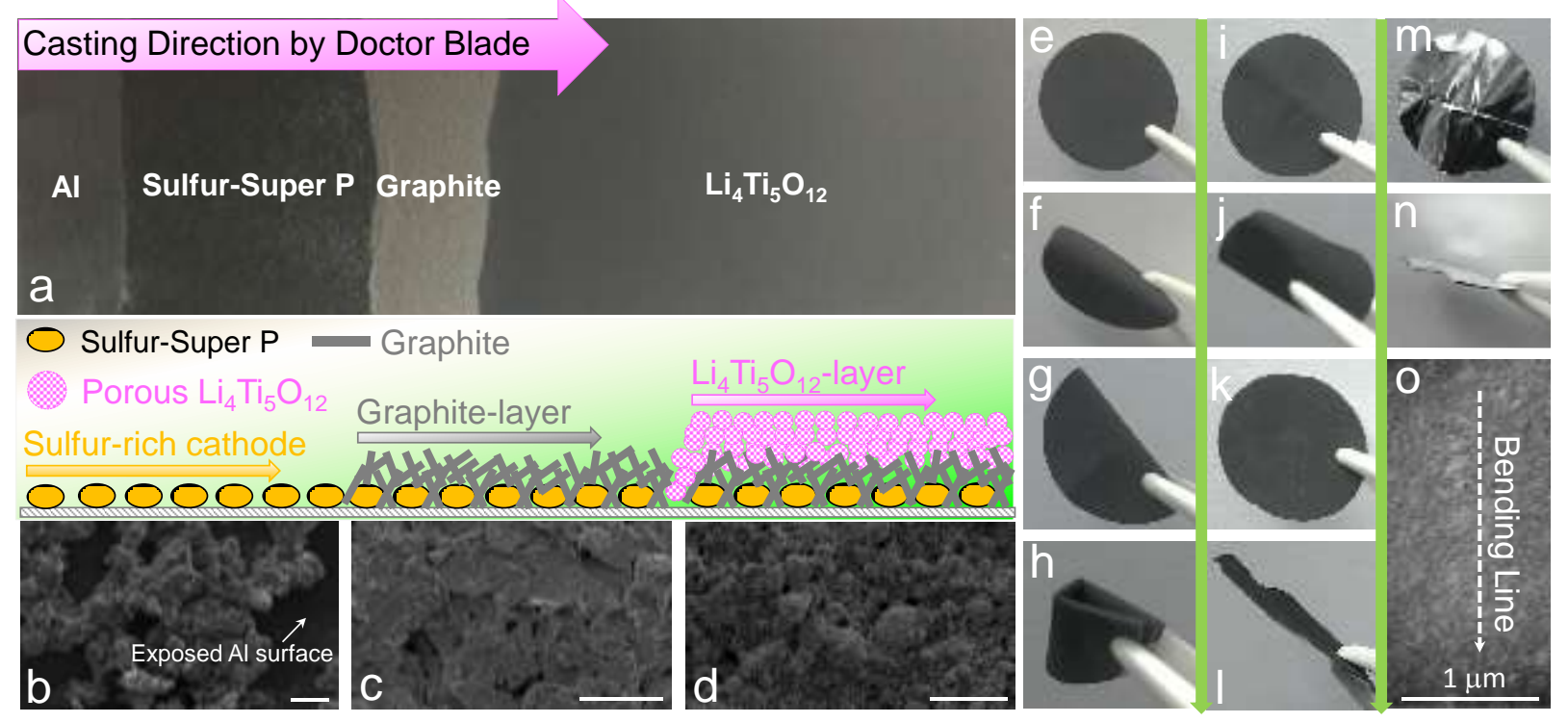

Figure S9. Multilayered electrode and bending test. (a) Digital photograph and schematic of multilayered electrode casting layer-by-layer. (b) Interfacial morphologies of sulfur-rich cathode, and covered by the (c) graphitic sheets and (d) porous LTO layer. (e) Pristine S/graphite/LTO electrode punched to circular shape. (f-j) Bending the S/graphite/LTO electrode along variable directions and angles. (k) Recovered electrode after bending test, viewed along the (b) positive side, (m) aluminum side and (n) anti-side. (o) SEM image of electrode alone the bending line. The scale bar is $25 \mu \mathrm{m}$.

A detail description of casting process: (i) First, the sulfur-rich cathode (90wt\% Sulfur-Super P:10 wt\% PVDF) was casted on aluminum foil (black layer); (ii) After drying, the 90wt\% graphite-10wt\% PVDF slurry was casted on the sulfur-rich cathode (Gray-layer); (iii) Finally, the LTO-Super P-PVDF (9:1:1 in mass ratio) slurry was casted on the graphite surface as the top layer (black-gray layer), giving rise to a multi-layered electrode. All slurry was formed in NMethyl-2-pyrrolidone (NMP) solution, and all coating was casted by doctor blade.

The contact between layers is fine for the following reasons: (i) The sulfur-super P particles casted on an Al foil are with certain roughness (Figure S9b). Thus, there is enough exposed Al surface and sufficient architectural pores allowing the penetration, contact and binding for the subsequent layer such as graphite-PVDF (Figure S9b); (ii) The covered graphitic layer is also rough and particularly rich of porosity (i.e., mainly resulted from the random accumulation of graphitic sheets), which can provide enough space contact with the final layer LTO-Super PPVDF (Figure S9c). (iii) Except the architectural contact of each layer, the PVDF in neighbor layers can well contact and re-bind together, because the casted slurry can re-dissolve the PVDF on bottom layer, thereby giving rise to a stable multi-layered electrode. 
The multilayered electrode can accommodate the volume variation for lithium polysulfides because of the following reasons: (i) First, the aggregated Sulfur-Super P particles on Al foil can leave a lot of exposed spaces with a very rough surface, which is the main free volume for holding the formed polysulfides and buffering the volume variation; (ii) The middle layer of mesoporous graphitic sheets in random accumulation can further bring additional architectural macro-pores, which can host the polysulfides; (iii) The top LTO layer is also rich of porosity, especially the observed meso/macro-pores on LTO particles (Figure S8). Thus, the constructed multilayer electrode have enough architectural spaces and intrinsic pores (e.g., meso-porous graphite, porous LTO) for the redistribution, suppression and adsorption of migrated polysulfides. Further, the multi-layered electrode consisting of rough Sulfur-Super P particles, graphitic sheets, macro-porous LTO can make the flexibility of electrode stronger because the different architectures in each layer can effectively buffer the volume and stress change during the charge/discharges.

The main reasons of selecting LTO as external layer are as follows: (i) "Zero-strain" in volume during the insertion/extraction of lithium ions ensure the stability of electrode, (ii) LTO is nonflammable, which guarantees the safety of the hybrid battery, (iii) The voltage around $1.55 \mathrm{~V}$ is located within the stable voltage-window of lithium-sulfur battery electrolyte (1.0 M LiTFSI in DOL/DME, $0.1 \mathrm{M} \mathrm{LiNO}_{3},<4.0 \mathrm{~V} v s . \mathrm{Li}_{/} \mathrm{Li}^{+}$). (iv) $\mathrm{LTO}$ is a standard material which can prove the concept more convincible. 

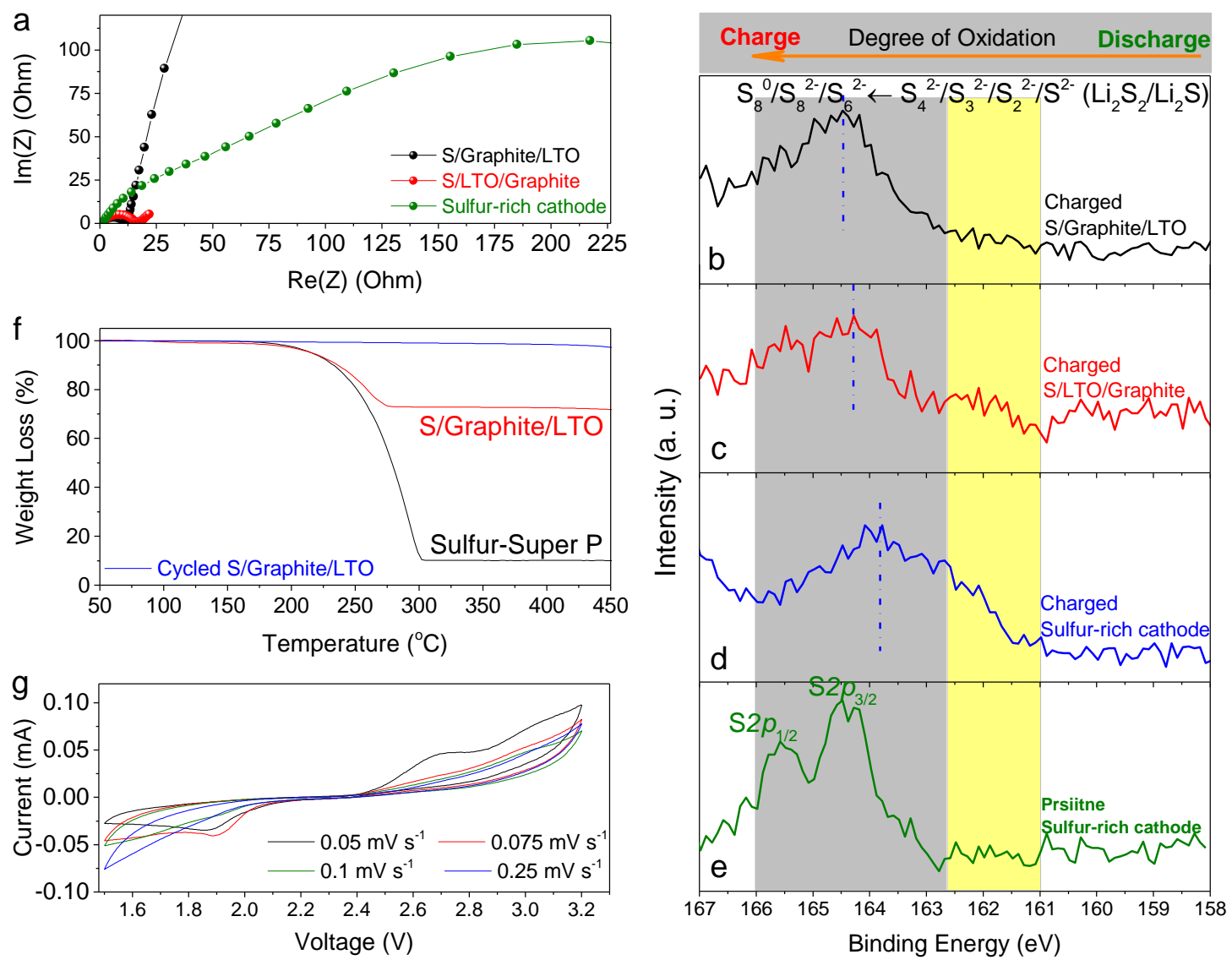

Figure S10. Characterization of cycled electrode. (a) Comparative EIS and (b-d) S2p spectra of cycled electrode. (e) S2p spectra of pristine sulfur-rich cathode before the cycle. (f) TGA analysis of pristine sulfur-rich electrode and S/graphite/LTO before and after cycle. (g) CV of pristine sulfur-rich cathode. The $\mathrm{S} 2 \mathrm{p}$ spectra of $\mathrm{Li}_{2} \mathrm{~S}_{2} / \mathrm{Li}_{2} \mathrm{~S}$ after the discharge mainly distribute from $162.5 \mathrm{eV}$ to $158 \mathrm{eV}$. In the charge process, the $\mathrm{S} 2 p$ peak position will move back to higher binding energy area as the oxidation degree of $\mathrm{S}^{2-}$. ${ }^{-S 15}$ Benefiting from the protection ability and higher electric conductivity of S/graphite/LTO, the oxidation degree of $\mathrm{S}^{2-}$ in charged sate is much higher than charged sulfur-rich cathode and S/LTO/graphite electrode which contains more amount of discharged product, as confirmed by the higher intensity of $\mathrm{S} 2 p$ peaks at 162.5 $\mathrm{eV}-161 \mathrm{eV}$ (yellow area) and lower peak value in gray area. 


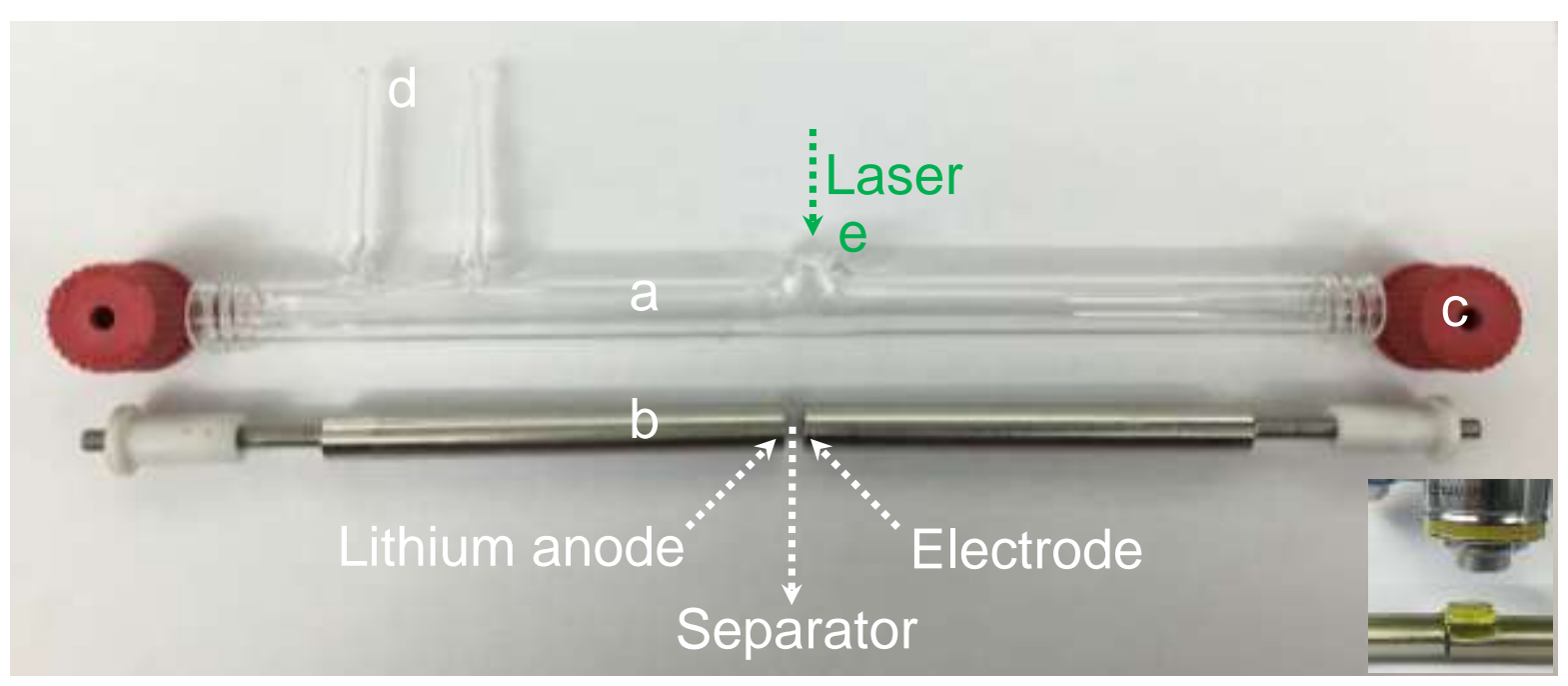

Figure S11. Schematic of designed glass battery. (a) Hollow glass tube, (b) long steal with polytetrafluoroethylene (PTFE) neck, where the anode of lithium, cathode of sulfur/graphite/LTO and separator were placed to assemble the battery, (c) red cap which were used to seal the PTFE neck, (d) spare hollow tubes which are available to fill and remove exhaust gas if necessary, such as in the case of lithium-oxygen battery. In this hybrid lithium battery, the small hollow tubes of (d) were sealed by hot-melt adhesive. The position of (e) on the hollow glass tube is a projecture with the flat surface for holding and investigating the electrolyte by laser during the collection of Raman spectrum. Inset is a photo of cycled battery in the test.
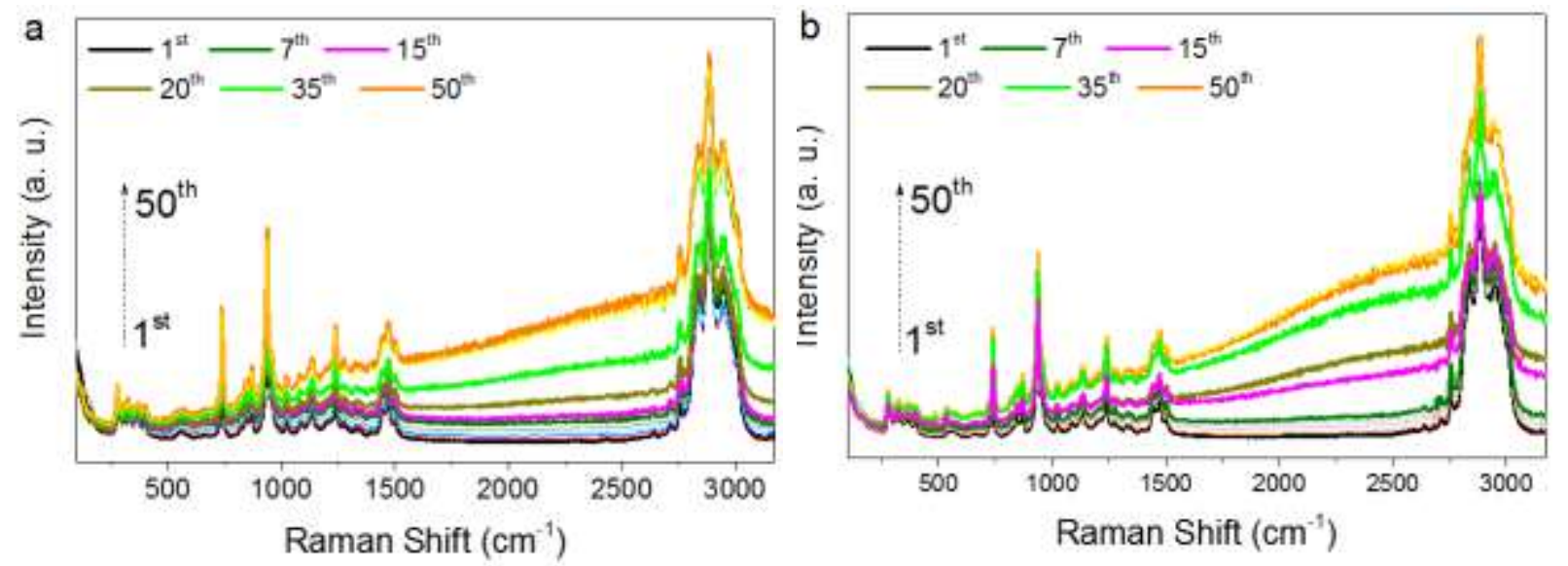

Figure S12. Operando Raman spectrum of electrolyte as cycling. Batteries with using (a) S/graphite/LTO cathode and pristine S-rich cathode without capping layer tested under the scan rate of $0.1 \mathrm{mV} \mathrm{s}^{-1}$ 


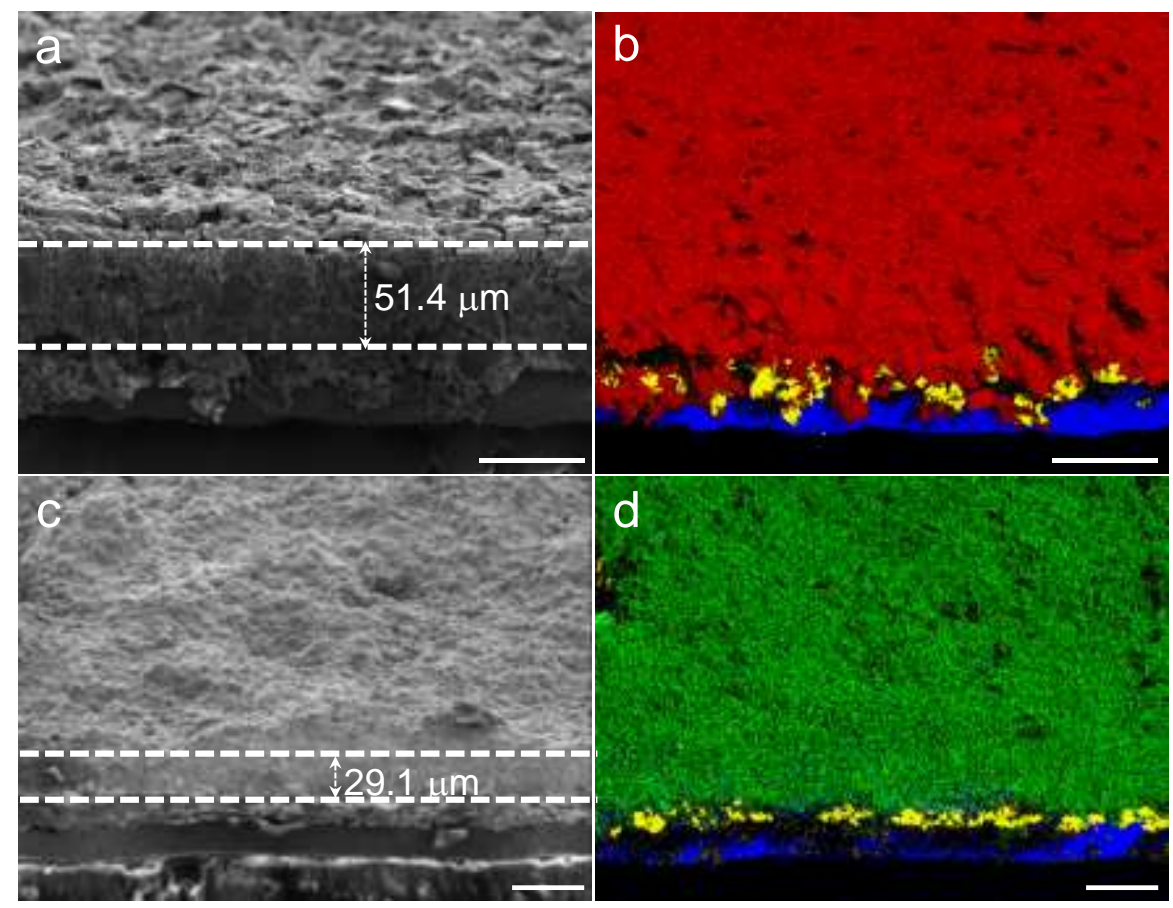

Figure S13. Surficial situation and morphology of hybridized electrode. The sulfur rich cathode covered by the $(\mathrm{a}, \mathrm{b})$ graphite and $(\mathrm{c}, \mathrm{d})$ LTO layer. The color of blue, yellow, red, and green present elements of aluminum, sulfur, carbon, and steric situation of LTO respectively. The mass density of graphite and LTO are $3.39 \mathrm{mg} \mathrm{cm}^{-2}$ with the thickness of $51.4 \mu \mathrm{m}$ and $29.1 \mu \mathrm{m}$. Scale bar: $100 \mu \mathrm{m}$. 


\section{References}

S1. Ji, X. L.; Lee, K. T.; Nazar, L. F. A Highly Ordered Nanostructured Carbon-Sulphur Cathode for Lithium-Sulphur Batteries. Nat. Mater. 2009. 8, 500-506.

S2. Seh, Z. W.; Li, W. Y.; Cha, J. J.; Zheng, G. Y.; Yang, Y.; McDowell, M. T.; Hsu, P. C.; Cui, Y. Sulphur-TiO $\mathrm{T}_{2}$ Yolk-Shell Nanoarchitecture with Internal Void Space for Long-Cycle Lithium-Sulphur Batteries. Nat. Commun. 2013. 4, 1331(1-6)

S3. Liu, J.; Yang, T. Y.; Wang, D. W.; Lu, G. Q. M.; Zhao, D. Y.; Qiao, S. Z. A Facile SoftTemplate Synthesis of Mesoporous Polymeric and Carbonaceous Nanospheres. Nat. Commun. 2013. 4, 2798(1-7).

S4. Lin, T. Q.; Tang, Y. F.; Wang, Y. M.; Bi, H.; Liu, Z. Q.; Huang, F. Q.; Xie, X. M.; Jiang, M. H. Scotch-tape-like Exfoliation of Graphite Assisted with Elemental Sulfur and GrapheneSulfur Composites for High-Performance Lithium-Sulfur Batteries. Energ. Environ. Sci. 2013. $6,1283-1290$.

S5. Zhang, B.; Qin, X.; Li, G. R.; Gao, X. P. Enhancement of Long Stability of Sulfur Cathode by Encapsulating Sulfur into Micropores of Carbon Spheres. Energ. Environ. Sci. 2010. 3, 1531-1537.

S6. Kim, H.; Lee, J.; Ahn, H.; Kim, O.; Park, M. J. Synthesis of Three-Dimensionally Interconnected Sulfur-Rich Polymers for Cathode Materials of High-Rate Lithium-Sulfur Batteries. Nat. Commun. 2015. 6, 7278(1-10).

S7. Lee, S. K.; Oh, S. M.; Park, E.; Scrosati, B.; Hassoun, J.; Park, M. S.; Kim, Y. J.; Kim, H.; Belharouak, I.; Sun, Y. K. Highly Cyclable Lithium-Sulfur Batteries with a Dual-Type Sulfur Cathode and a Lithiated $\mathrm{Si} / \mathrm{SiO}_{\mathrm{x}}$ Nanosphere Anode. Nano Lett. 2015. 15, 2863-2868.

S8. Fan, Q.; Liu, W.; Weng, Z.; Sun, Y. M.; Wang, H. L. Ternary Hybrid Material for HighPerformance Lithium-Sulfur Battery. J. Am. Chem. Soc. 2015. 137, 12946-12953.

S9. Zhou, W.; Xiao, X.; Cai, M.; Yang, L. Polydopamine-coated, Nitrogen-Doped, Hollow Carbon-Sulfur Double-Layered Core-Shell Structure for Improving Lithium-Sulfur Batteries. Nano Lett. 2014. 14, 5250-5256.

S10. Wei, S. Y.; Ma, L.; Hendrickson, K. E.; Tu, Z. Y.; Archer, L. A. Metal-Sulfur Battery Cathodes Based on PAN Sulfur Composites. J. Am. Chem. Soc. 2015. 137, 12143-12152.

S11. Liang, X.; Hart, C.; Pang, Q.; Garsuch, A.; Weiss, T.; Nazar, L. F. A Highly Efficient Polysulfide Mediator for Lithium-Sulfur Batteries. Nat. Commun. 2015. 6, 5682(1-8). 
S12. Hwang, J. Y.; Kim, H. M.; Lee, S. K.; Lee, J. H.; Abouimrane, A.; Khaleel, M. A.; Belharouak, I.; Manthiram, A.; Sun, Y. K. High-Energy, High-Rate, Lithium-Sulfur Batteries: Synergetic Effect of Hollow $\mathrm{TiO}_{2}$-Webbed Carbon Nanotubes and a Dual Functional Carbon-Paper Interlayer. Adv. Energy Mater. 2015, 6, 1501480(1-7).

S13. Zhao, M. Q.; Zhang, Q.; Huang, J. Q.; Tian, G. L.; Nie, J. Q.; Peng, H. J.; Wei, F. Unstacked Double-Layer Templated Graphene for High-Rate Lithium-Sulphur Batteries. Nat. Commun. 2014. 5, 3410(1-8).

S14. Liang, X.; Garsuch, A.; Nazar, L. F., Sulfur Cathodes Based on Conductive Mxene Nanosheets for High-Performance Lithium-Sulfur Batteries. Angew Chem. Int. Ed. 2015. 54, 3907-3911.

S15. Kim, H. S.; Arthur, T. S.; Allred, G. D.; Zajicek, J.; Newman, J. G.; Rodnyansky, A. E.; Oliver, A. G.; Boggess, W. C.; Muldoon, J. Structure and Compatibility of a Magnesium Electrolyte with a Sulphur Cathode. Nat. Commun. 2011, 2, 427(1-6).

S16. Fujimori, T.; Morelos-Gomez, A.; Zhu, Z.; Muramatsu, H.; Futamura, R.; Urita, K.; Terrones, M.; Hayashi, T.; Endo, M.; Hong, S. Y.; Choi, Y. C.; Tomanek, D.; Kaneko, K. Conducting Linear Chains of Sulphur Inside Carbon Nanotubes. Nat. Commun. 2013, 4, 2162(1-8).

S17. Su, Y. S.; Fu, Y.; Cochell, T.; Manthiram, A. A Strategic Approach to Recharging LithiumSulphur Batteries for Long Cycle Life. Nat. Commun. 2013, 4, 2985(1-8).

S18. Agostini, M.; Xiong, S.; Matic, A.; Hassoun, J. Polysulfide-containing Glyme-Based Electrolytes for Lithium Sulfur Battery. Chem. Mater. 2015, 27, 4604-4611. 